\title{
Erratum to: Association of SCD1 and DGAT1 SNPs with the intramuscular fat traits in Chinese Simmental cattle and their distribution in eight Chinese cattle breeds
}

\author{
X. X. Wu - Z. P. Yang $\cdot$ X. K. Shi $\cdot$ J. Y. Li • \\ D. J. Ji $\cdot$ Y. J. Mao $\cdot$ L. L. Chang $\cdot$ H. J. Gao
}

Published online: 14 March 2013

(C) Springer Science+Business Media Dordrecht 2013

Erratum to: Mol Biol Rep (2012) 39:1065-1071

DOI 10.1007/s11033-011-0832-0

Author affiliation was incorrectly published as Chinese Academy of Agricultural Sciences and should be read as Yangzhou University.

The online version of the original article can be found under doi: 10.1007/s11033-011-0832-0.

X. X. Wu $\cdot$ Z. P. Yang $(\bowtie) \cdot$ X. K. Shi .

D. J. Ji · Y. J. Mao · L. L. Chang

Key Lab of Animal Genetics, Breeding and Molecular Design of Jangsu Province, College of Animal Science and Technology,

Yangzhou University, Yangzhou 225009,

People's Republic of China

e-mail: yzp@yzu.edu.cn

J. Y. Li (凹) · D. J. Ji · H. J. Gao

Institute of Animal Science, Yangzhou University,

Beijing 100193, People's Republic of China

e-mail: JL1@iascaas.net.cn 